\section{Reporting of sources of funding in systematic reviews in periodontology and implant dentistry}

\author{
C. M. Faggion $\mathrm{Jr}_{1}^{* 1,2}$ M. Atieh ${ }^{3}$ and D. G. Zanicotti ${ }^{3}$
}



Industry-supported clinical trials may present better outcomes than those supported by other sources. The aim of this paper was to assess whether systematic reviews (SRs) published in periodontology and implant dentistry report and discuss the influence of funding sources on study results. Two reviewers conducted a comprehensive search in PubMed and the Cochrane Database of Systematic Reviews independently and in duplicate to identify SRs published up to 11 November 2012. Speciality dental journals and the reference lists of included SRs were also scrutinised. Information on the reporting and discussion of funding sources of primary studies included in the SRs was extracted independently and in duplicate. Any disagreement regarding SR selection or data extraction was discussed until consensus was achieved. Of 146 SRs included in the assessment, only $45(31 \%)$ reported the funding sources of primary studies. Fourteen (10\%) SRs discussed the potential influence of funding sources on study results, that is, sponsorship bias. Funding sources are inadequately reported and discussed in SRs in periodontology and implant dentistry. Assessment, reporting, and critical appraisal of potential sponsorship bias of meta-analytic estimates are paramount to provide proper guidance for clinical treatments.

\section{INTRODUCTION}

Systematic reviews (SRs) involve the analysis of all available evidence to answer a research question in a precise and unbiased way. ${ }^{1}$ They differ from narrative reviews by adhering to a strict predefined methodology governing factors such as inclusion/ exclusion criteria and search strategies, allowing for the reproducibility of findings. Meta-analyses (MAs) quantitatively integrate the results of studies included in SRs using specific statistical techniques (http://www.cochrane.org/glossary). Some researchers consider MAs to be the source of the highest grade of evidence available regarding the efficacy of an intervention. ${ }^{2}$

Several sources of bias in studies included in $\mathrm{SRs}^{3}$ may, however, reduce our confidence in the final meta-analytic estimates, even when those reviews are correctly planned and conducted according to known guidelines, such as preferred

\footnotetext{
'Department of Periodontology, Faculty of Dentistry, University of Münster, Münster, Germany: ${ }^{2}$ Department of Oral Sciences, Faculty of Dentistry, University of Otago, Dunedin, New Zealand; ${ }^{3}$ Sir John Walsh Research Institute, Faculty of Dentistry, University of Otago, Dunedin, New Zealand

${ }^{*}$ Correspondence to: Clovis Mariano Faggion Jr Email: clovisfaggion@yahoo.com
}

\section{Refereed Paper}

Accepted 4 November 2013

DOI: $110.1038 /$ sj.bdj.2014.47

${ }^{\circ}$ British Dental Journal 2014; 214: 109-112 reporting items for systematic reviews and meta-analysis (PRISMA) and meta-analysis of observational studies in epidemiology (MOOSE). ${ }^{4,5}$ Threats to the validity of an SR, such as publication bias and variability in the quality of studies pooled, ${ }^{2}$ should be taken into account when the results are critically assessed. Potential sponsorship bias should also be considered. Evidence suggests that the outcomes of industryfunded trials may be more inflated and better than those of trials supported by other sources. ${ }^{6}$ Readers of SRs should be aware that a body of evidence containing a large number of industry-funded primary trials may provide biased meta-analytic results. Authors of SRs must therefore report information on the funding of trials included in these studies.

The objective of this paper was to assess whether authors of SRs published in periodontology and implant dentistry adequately report the funding sources of primary studies included in those reviews.

\section{MATERIALS AND METHODS}

\section{Literature search}

The full literature search strategy for this manuscript has been described elsewhere. ${ }^{7}$ Briefly, the PubMed and Cochrane Database of Systematic Reviews databases were searched to identify abstracts of SRs on the efficacy of interventions published in the fields of periodontology and implant dentistry, with the last search conducted on 11 November 2012. Eligible SRs contained MAs. The previous study ${ }^{7}$ focused on the quality of reporting in abstracts of SRs. To increase the sensitivity of the literature search, the records of ten high-impact journals in periodontology and implant dentistry were also searched manually to identify additional SRs published between November 1990 and November 2012. The reference lists of included papers were also scrutinised to identify potentially eligible SRs. The literature search was performed independently and in duplicate by two authors. Any disagreement regarding the selection and inclusion of papers was resolved by discussion and consensus between at least two reviewers. Any persisting disagreement was resolved by a third reviewer (MA).

\section{Criteria for assessment}

Two authors (CMF and DGZ) retrieved the following information from each SR independently and in duplicate: (a) reporting of funding sources of primary studies included, (b) discussion of potential sponsorship bias, (c) statistical or graphical (that is, funnel plot) assessment of publication bias, and (d) reporting of the SR funding source. These data were entered 
directly into a table in dichotomous (yes/no) format to indicate whether each criterion was met. Any discrepancy in extracted information was resolved by discussion until consensus was achieved. The third reviewer (MA) made final decisions in cases of non-consensus between the first and last authors.

\section{RESULTS}

One hundred and forty-six SRs were included in the assessment. The authors of 45 (31\%) SRs reported the funding sources of primary studies included. The reporting of sponsorship in SRs seems to have improved in recent years, but the number of publications has also increased (Table 1).

The authors of $14(10 \%)$ SRs discussed the possible influence of sponsorship on the meta-analytic findings (Table 2). This potential influence was assessed objectively (for example, sensitivity analysis) in four SRs, whereas the remaining SRs reported the presence of potential sponsorship bias without carrying out any analysis. Three SRs found no difference among sources of funding, ${ }^{8-10}$ whereas one $\mathrm{SR}^{11}$ observed that industry-funded trials produced more favourable results.

Thirty (21\%) SRs attempted to investigate publication bias, 98 (67\%) SRs contained no description of such assessment, and 18 (12\%) SRs reported that the investigation of publication bias was not possible due to the small number of primary studies included.

Industry funding was reported in $2 \%$ of SRs. Forty (27\%) SRs reported self-funding or no receipt of external funding, and were thus considered to have received nonindustry support. However, most $(\mathrm{n}=103$, 71\%) SRs provided no information about funding.

\section{DISCUSSION}

The omission of information about funding sources in the majority of SRs assessed in this study is alarming, as readers require comprehensive information of this type to adequately understand the potential influence of sponsorship bias on the results of these reviews. Accumulating evidence overwhelmingly indicates that industry-funded trials generate more favourable results than studies with other sources of support. ${ }^{6,12-18}$ For example, annual dental implant failure rates reported in industry-associated trials are significantly lower than those reported in trials without industry support. ${ }^{19}$ Dental practitioners' underestimation of the impact of sponsorship bias may influence clinical decision making. In addition,

\begin{tabular}{|c|c|c|c|}
\hline $\begin{array}{l}\text { Year of } \\
\text { publication }\end{array}$ & $\begin{array}{l}\text { Number of systematic } \\
\text { reviews published }\end{array}$ & $\begin{array}{l}\text { Sponsorship reported } \\
N(\%)\end{array}$ & $\begin{array}{l}\text { Sponsorship discussed } \\
N(\%)\end{array}$ \\
\hline $1992-2001^{*}$ & 9 & $0(0)$ & $0(0)$ \\
\hline 2002 & 10 & $6(60)$ & $1(10)$ \\
\hline 2003 & 11 & 7 (64) & 1 (9) \\
\hline 2004 & 3 & $1(33)$ & $0(0)$ \\
\hline 2005 & 9 & $2(22)$ & $2(22)$ \\
\hline 2006 & 4 & $1(25)$ & $0(0)$ \\
\hline 2007 & 12 & $2(17)$ & $1(8)$ \\
\hline 2008 & 13 & $4(29)$ & $1(8)$ \\
\hline 2009 & 14 & $5(36)$ & $2(14)$ \\
\hline 2010 & 20 & $6(30)$ & $1(5)$ \\
\hline 2011 & 13 & $5(38)$ & $2(15)$ \\
\hline 2012 & 28 & $6(21)$ & $3(11)$ \\
\hline
\end{tabular}

industry sponsorship may influence the ways in which clinical trials are planned, conducted, and reported. ${ }^{6,20}$ For example, industry-funded trials may include unbalanced comparators (that is, test and control groups), which promote positively skewed assessment of the product or technique of interest. ${ }^{21}$ Moreover, such trials frequently use placebo-control groups, rather than active or positive controls, ${ }^{22,23}$ which prevents determination of whether a new therapy is more effective (or does less harm) than proven standard therapies - so-called gold standards. ${ }^{24}$ Such methodological issues concerning the comparison of treatment groups may raise ethical concerns about the conduction of the clinical trial. ${ }^{25}$

Few SRs included in this analysis assessed the potential influence of sponsorship bias in primary studies on meta-analytic estimates. This omission may be the result of the lack of detailed information in primary studies about financial support and conflicts of interest (COIs), such as authors' employment by supporting companies, stock ownership, and receipt of grants and research materials. Furthermore, SRs in the present sample assessed a wide variety of products and/or techniques. In addition, only some of the appraised outcomes in each MA were relevant to the conclusions. Thus, it can be unreliable to compare the potential influence of sponsorship bias on meta-analytic estimates in SRs that report primary funding source to those that fail to report it.

Selective outcome reporting (partial publication of findings, depending on COIs) is a concern, especially in reports of industry-supported randomised controlled trials (RCTs). ${ }^{26}$ Inadequate reporting of outcomes may interfere with the critical interpretation of evidence from these trials, and the suppression of non-significant findings could lead to the implementation of harmful therapies. ${ }^{27}$ Moreover, industry support seems to contribute to publication bias characterised by the greater likelihood of reporting on trials with significant (versus nonsignificant) results or delayed publication of trial findings because of potential COIs. ${ }^{28}$ Similarly, the strengthening of publication policies in scientific journals may result in bias by creating potential barriers to publication. ${ }^{29}$ Only $21 \%$ of SRs in the present sample used statistical or graphical methods to investigate publication bias.

Despite concern about the potential bias presented by industry sponsorship, one must note that many studies included in SRs may not have been performed without industry funding. Grants from non-profit organisations (for example, governmental organisations, foundations) and universities are usually limited and cannot solely support the large number of studies being conducted on diverse topics. Implant dentistry, in particular, benefits from associations between industry and researchers because the costs involved in purchasing dental implants and surgical kits for large-scale research can be prohibitive. The donation of materials by industry bodies enables researchers to use grants to cover other costs, such as laboratory materials and equipment, consumables, and supporting personnel. However, although cooperation between industry and academia seems to be relevant in the current context, SRs should provide detailed and explicit information about the nature of this cooperation. 


\section{Table 2 Methods of assessing primary studies' funding sources in systematic reviews}

\begin{tabular}{|c|c|}
\hline $\begin{array}{l}\text { Systematic } \\
\text { reviews }\end{array}$ & Comments \\
\hline $\begin{array}{l}\text { Al-Hamdan } \\
\text { et al. } 2003^{32}\end{array}$ & $\begin{array}{l}\text { The authors presented results and discussed the impact of sponsorship in regenerative } \\
\text { based root coverage. Nine studies included in the SR were company funded and } 31 \text { were } \\
\text { not. They concluded that corporate sponsorship resulted in significantly improved root } \\
\text { coverage but with less clinical attachment level gains. Though the initial recession and } \\
\text { attachment level were smaller for sponsored studies. }\end{array}$ \\
\hline $\begin{array}{l}\text { Angelillo } \\
\text { et al. } 2002^{33}\end{array}$ & $\begin{array}{l}\text { Meta-analysis performed by the authors showed that the plaque index reduction was kept } \\
\text { unchanged over time (one day to } 24 \text { weeks) for industry supported studies whereas for } \\
\text { independent studies the reduction was only seen for a short period of time (one day) when } \\
\text { compared to placebo. }\end{array}$ \\
\hline $\begin{array}{l}\text { Esposito } \\
\text { et al. } 2005^{34}\end{array}$ & $\begin{array}{l}\text { The authors declared that all trials included in the SR were commercially funded. So, an } \\
\text { analysis on the effect of type of funding on the outcomes was not performed, although } \\
\text { the authors discussed the possibility of commercial bias. }\end{array}$ \\
\hline $\begin{array}{l}\text { Esposito } \\
\text { et al. } 2007^{35}\end{array}$ & $\begin{array}{l}\text { Authors reported that } 12 \text { of } 16 \text { included trials were commercially funded. However, } \\
\text { although they reported that 'there could be bias in this area', no analysis on the influence } \\
\text { of sponsorship was presented. }\end{array}$ \\
\hline $\begin{array}{l}\text { Esposito } \\
\text { et al. } 2009^{36}\end{array}$ & $\begin{array}{l}\text { The information was derived from risk of bias tables: The authors affirm that when } \\
\text { industry-funded studies were included, they did not consider the outcomes to be biased. }\end{array}$ \\
\hline $\begin{array}{l}\text { Esposito } \\
\text { et al. } 2009^{37}\end{array}$ & $\begin{array}{l}\text { The information was derived from the risk of bias tables: in three studies the sponsorship } \\
\text { bias was considered unclear due to donations of material. In one industry-funded study } \\
\text { the sponsorship bias was considered present due to the presentation of combined data. } \\
\text { Another study was considered free of bias due to donation of materials (resorbable screws). } \\
\text { Also, one study that received PRP equipment as a gift was not considered biased. }\end{array}$ \\
\hline $\begin{array}{l}\text { Esposito } \\
\text { et al. } 2010^{38}\end{array}$ & $\begin{array}{l}\text { The information was derived from the risk of bias tables: The SR authors considered unclear } \\
\text { risk of bias for the free of other bias domain, because the producer of the tested material } \\
\text { supported the study. The SR authors suggest that other levels of economic association } \\
\text { such as donation of materials were considered irrelevant for generating sponsorship bias. }\end{array}$ \\
\hline $\begin{array}{l}\text { Esposito } \\
\text { et al. } 2012^{9}\end{array}$ & $\begin{array}{l}\text { The authors quote the possibility of commercial pressure to evaluate certain interventions } \\
\text { and not others. This is due to manufactures supporting the majority of included studies. }\end{array}$ \\
\hline $\begin{array}{l}\text { Esposito } \\
\text { et al. } 2012^{10}\end{array}$ & $\begin{array}{l}\text { The information was derived from the risk of bias tables: the free of other bias domain was } \\
\text { considered of high risk of bias in one study, because it was commercially supported and } \\
\text { two patients were excluded from the supported intervention. }\end{array}$ \\
\hline $\begin{array}{l}\text { Haps et al. } \\
2008^{39}\end{array}$ & $\begin{array}{l}\text { Authors reported that most studies included in the systematic review had authors from } \\
\text { industry or were industry sponsored. They, nevertheless, only commented that industry } \\
\text { sponsorship might be considered a risk for publication bias, because industry tends to } \\
\text { discourage the publication of negative results. }\end{array}$ \\
\hline $\begin{array}{l}\text { Kalsi et al. } \\
2011^{40}\end{array}$ & $\begin{array}{l}\text { The authors declared that 'the only limitation of this review is the limited sample size } \\
\text { because all the studies were self-funded as compared with other studies that were either } \\
\text { sponsored or funded by some industry'. Nevertheless, they did not comment any potential } \\
\text { influence of type of sponsorship on the meta-analytic results. }\end{array}$ \\
\hline $\begin{array}{l}\text { Robinson } \\
\text { et al. } 2005^{41}\end{array}$ & $\begin{array}{l}\text { The authors reported there was no evidence of a difference in effect estimates when a } \\
\text { sensitivity analysis was conducted for trials that did not mention commercial funding. } \\
\text { However, } 67 \% \text { of the included papers were supported by the Industry and the remaining } \\
\text { ones were unclear. Therefore sponsorship bias cannot be excluded. }\end{array}$ \\
\hline $\begin{array}{l}\text { Sambunjak } \\
\text { et al. } 2011^{42}\end{array}$ & $\begin{array}{l}\text { The authors performed sensitive analysis and reported that 'excluding the seven industry- } \\
\text { sponsored studies from the analysis did not significantly change the effect estimates for } \\
\text { both gingivitis and plaque outcome, in all observed time points (analyses not shown).' } \\
\text { However, all the remaining papers included in the analysis (unclear to sponsorship) were } \\
\text { conducted by authors whose affiliations shows possible or real connections to the industry } \\
\text { (as shown in the results). Therefore sponsorship bias cannot be excluded. }\end{array}$ \\
\hline $\begin{array}{l}\text { Sohrabi etal. } \\
2012^{43}\end{array}$ & $\begin{array}{l}\text { The authors described how the authors of primary studies included in the SR reported the } \\
\text { type of funding or the association of authors with industry. Nevertheless, no attempt to } \\
\text { assess the influence of type of funding on the estimates was performed. }\end{array}$ \\
\hline
\end{tabular}

Clinicians and patients often depend on the findings of SRs to support decisionmaking. With the continual increase in the number of SRs published, and given the advantages of such studies over small clinical trials, ${ }^{1}$ the reporting of any threat of bias in the assessment of treatment effects must be as transparent as possible. Moreover, clinicians may have difficulty understanding and interpreting the findings of SRs, ${ }^{11}$ which could be alleviated by SR authors' provision of a critical discussion of potential sponsorship bias.

\section{RECOMMENDATIONS}

Authors should take the following measures to improve the assessment and reporting of sponsorship bias in SRs:

- Obtain the original protocols of primary studies (that is, RCTs), which are normally recorded in official registries (for example, clinicaltrials.gov), to assess potential selective outcome reporting

- Conduct sensitivity analyses when they suspect that funding sources and/or disclosed COIs have influenced metaanalytic estimates ${ }^{8}$
- Report in detail the funding sources of primary studies included in SRs $\mathrm{S}^{30,31}$ and the authors' potential financial ties to industry. Similarly, they should report their own potential COIs, for example by describing the sources of financial support for SRs and the authors' industry associations.

\section{Montori V M, Swiontkowski M F, Cook D J.} Methodologic issues in systematic reviews and metaanalyses. Clin Orthop Relat Res 2003; 413: 43-54.

2. Sutton A J, Abrams K R, Jones D R. An illustrated guide to the methods of meta-analysis. J Eval Clin Pract 2001; 7: 135-148.

3. Higgins J P, Altman D G, Gøtzsche P C et al. The Cochrane Collaboration's tool for assessing risk of bias in randomised trials. BMJ 2011; 343: d5928. 4. Liberati A, Altman D G, Tetzlaff J et al. The PRISMA statement for reporting systematic reviews and meta-analyses of studies that evaluate health care interventions: explanation and elaboration. PLOS Med 2009; 6: e1000100.

5. Stroup D F, Berlin J A, Morton S C et al. Metaanalysis of observational studies in epidemiology: a proposal for reporting. Meta-analysis Of Observational Studies in Epidemiology (MOOSE) group. JAMA 2000; 283: 2008-2012.

6. Lundh A, Sismondo S, Lexchin J, Busuioc O A, Bero L. Industry sponsorship and research outcome. Cochrane Database Syst Rev 2012; 12: MR000033.

7. Faggion C M Jr., Liu J, Huda F, Atieh M. Quality of reporting in abstracts of systematic reviews with meta-analyses in Periodontology and Implant Dentistry. J Periodontal Res 2013; epub ahead of print 8. Viswanathan M, Ansari M T, Berkman N D et al. Assessing the risk of bias of individual studies in systematic reviews of health care interventions. Methods guide for effectiveness and comparative effectiveness reviews. Rockville, MD: Agency for Healthcare Research and Quality (US), 2008-2012.

9. Esposito M, Grusovin M G, Worthington H V. Interventions for replacing missing teeth: treatment of peri-implantitis. Cochrane Database Syst Rev 2012; 1: CD004970.

10. Esposito M, Maghaireh $H$, Grusovin M G, Ziounas I, Worthington $\mathrm{H} \mathrm{V}$. Interventions for replacing missing teeth: management of soft tissues for dental implants. Cochrane Database Syst Rev 2012; 2: CD006697.

11. Lai N M, Teng $C L$, Lee $M$ L. Interpreting systematic reviews: are we ready to make our own conclusions? A cross-sectional study. BMC Med 2011; 9: 30.

12. Yaphe J, Edman R, Knishkowy B, Herman J. The association between funding by commercial interests and study outcome in randomized controlled drug trials. Fam Pract 2001; 18: 565-568. 13. Baker C B, Johnsrud M T, Crismon M L, Rosenheck R A, Woods S W. Quantitative analysis of sponsorship bias in economic studies of antidepressants. $\mathrm{Br} J$ Psychiatry 2003; 183: 498-506.

14. Bhandari M, Busse J W, Jackowski D et al. Association between industry funding and statistically significant pro-industry findings in medical and surgical randomized trials. CMAJ 2004; 170: 477-480.

15. Shah $R V_{1}$, Albert $T J$, Bruegel-Sanchez $V$, Vaccaro $A R$, Hilibrand A S, Grauer J N. Industry support and correlation to study outcome for papers published in Spine. Spine (Phila Pa 1976) 2005; 30: 1099-1104.

16. Kelly R E Jr, Cohen L J, Semple R J et al. Relationship between drug company funding and outcomes of clinical psychiatric research. Psychol Med 2006: 36: $1647-1656$.

17. Khan S N, Mermer M J, Myers E, Sandhu H S. The roles of funding source, clinical trial outcome, and quality of reporting in orthopedic surgery literature Am J Orthop (Belle Mead NJ) 2008; 37: E205-212.

18. Nkansah N, Nguyen T, Iraninezhad H, Bero L. Randomized trials assessing calcium supplementation in healthy children: relationship between industry sponsorship and study outcomes. Public Health Nutr 2009; 12: 1931-1937. 
19. Popelut A, Valet F, Fromentin O, Thomas A, Bouchard $P$. Relationship between sponsorship and failure rate of dental implants: a systematic approach. PLoS One 2010; 5: e10274.

20. Elliott D B. Industry-funded research bias and conflicts of interest. Ophthalmic Physiol Opt 2013; 33: $1-2$.

21. Djulbegovic B, Lacevic M, Cantor A et al. The uncertainty principle and industry-sponsored research. Lancet 2000; 356: 635-638.

22. Lathyris D N, Patsopoulos N A, Salanti G, loannidis $J$ P. Industry sponsorship and selection of comparators in randomized clinical trials. Eur J Clin Invest 2010; 40: 172-182.

23. Estellat C, Ravaud P. Lack of head-to-head trials and fair control arms: randomized controlled trials of biologic treatment for rheumatoid arthritis. Arch Intern Med 2012; 172: 237-244.

24. Garattini $S$, Bertele' V. Ethics in clinical research. J Hepatol 2009; 51: 792-797.

25. Rothman K J, Michels K B. The continuing unethical use of placebo controls. N Engl J Med 1994; 331: 394-398.

26. Vedula S S, Bero L, Scherer R W, Dickersin K Outcome reporting in industry-sponsored trials of gabapentin for off-label use. N Engl J Med 2009; 361: 1963-1971.

27. Chan A W, Altman D G. Identifying outcome reporting bias in randomised trials on PubMed: review of publications and survey of authors. BMJ 2005; 330: 753.

28. Lee $K$, Bacchetti P, Sim I. Publication of clinical trials supporting successful new drug applications: a literature analysis. PLos Med 2008; 5: e191.

29. Bauchner H. Editorial policies for clinical trials and the continued changes in medical journalism. JAMA 2013; 310: 149-150

30. Shea B J, Grimshaw J M, Wells $G$ A et al. Development of AMSTAR: a measurement tool to assess the methodological quality of systematic reviews. BMC Med Res Methodol 2007; 7: 10

31. Roseman M, Milette K, Bero L A et al. Reporting of conflicts of interest in meta-analyses of trials of pharmacological treatments. JAMA 2011; 305: 1008-1017.

32. Al-Hamdan $K$, Eber $R$, Sarment $D$, Kowalski C, Wang H L. Guided tissue regeneration-based root coverage: meta-analysis. J Periodontol 2003; 74: 1520-1533.

33. Angelillo I F, Nobile C G, Pavia M. Evaluation of the effectiveness of a pre-brushing rinse in plaque removal: a meta-analysis. J Clin Periodonto/ 2002; 29: 301-309.

34. Esposito M, Grusovin M G, Coulthard $P_{\text {, Thomsen }} \mathrm{P}_{\text {, }}$ Worthington H V. A 5-year follow-up comparative analysis of the efficacy of various osseointegrated dental implant systems: a systematic review of randomized controlled clinical trials. Int J Oral Maxillofac Implants 2005; 20: 557-568

35. Esposito M, Murray-Curtis L, Grusovin M, Coulthard $\mathrm{P}$, Worthington $\mathrm{H}$. Interventions for replacing missing teeth: different types of dental implants. Cochrane Database Syst Rev 2007; 4: CD003815.

36. Esposito M, Grusovin M, Papanikolaou N, Coulthard $\mathrm{P}$, Worthington $\mathrm{H}$. Enamel matrix derivative (Emdogain) for periodontal tissue regeneration in intrabony defects. Cochrane Database of Syst Rev 2009; 4: CD003875.

37. Esposito M, Grusovin M, Felice P, Karatzopoulos G, Worthington $\mathrm{H}$, Coulthard P. Interventions for replacing missing teeth: horizontal and vertical bone augmentation techniques for dental implant treatment. Cochrane Database Syst Rev 2009; 4: CD003607.

38. Esposito M, Grusovin M G, Rees J et al. Interventions for replacing missing teeth: augmentation procedures of the maxillary sinus. Cochrane Database Syst Rev 2010; 3: CD008397.

39. Haps S, Slot D, Berchier C, Van der Weijden G. The effect of cetylpyridinium chloride-containing mouth rinses as adjuncts to toothbrushing on plaque and parameters of gingival inflammation: a systematic review. Int J Dent Hyg 2008. 6: 290-303.

40. Kalsi R, Vandana K, Prakash S. Effect of local drug delivery in chronic periodontitis patients: a metaanalysis. J Indian Soc Periodontol 2011; 15: 304-309.

41. Robinson P, Deacon S, Deery C et al. Manual versus powered toothbrushing for oral health. Cochrane Database Syst Rev 2005; 2: CD002281.

42. Sambunjak D, Nickerson J W, Poklepovic T et al. Flossing for the management of periodontal diseases and dental caries in adults. Cochrane Database Syst Rev 2011; 12: CD008829.

43. Sohrabi K, Saraiya V, Laage T A, Harris M, Blieden M, Karimbux N. An evaluation of bioactive glass in the treatment of periodontal defects: a meta-analysis of randomized controlled clinical trials. J Periodontol 2012; 83: 453-464. 